\title{
EVOLUCIÓN HISTÓRICA DE CEMENTOS MEXICANOS: UN GRUPO ECONÓMICO DE CAPITAL NACIONAL
}

Beatriz Pérez Sánchez*, Andrés Guzmán Sala**, Armando Mayo Castro***, Ramón Humberto Heredia Mateos ${ }^{\star * * *}$

\begin{abstract}
Pérez-Sánchez B., Guzmán-Sala A., Mayo-Castro A., Heredia-Mateos R.H. Evolución histórica de Cementos Mexicanos: Un grupo económico de capital nacional. Hitos de Ciencias Económico Administrativas 2013;19 (55): 115-130.
\end{abstract}

\section{RESUMEN}

Objetivo: Conocer la evolución histórica de una gran empresa de capital nacional y abordar las estrategias que ha puesto en práctica hasta constituirse en un gran corporativo o grupo económico. Se parte del enfoque del devenir histórico en el que prevalece el análisis de los orígenes y evolución de la empresa. Por ende, predomina la crónica y las descripciones, reúne acontecimientos de la vida nacional y local de Monterrey, con la guía de un orden cronológico, logrando establecer planteamientos analíticos.

Material y método: Los métodos que se utilizaron fueron el método histórico-crítico, el método analítico con un enfoque dinámico y el método comparativo. Se utilizaron los enfoques: 1) regional, 2) de origen histórico y 3 ) de estrategias corporativas y organizaciones. El enfoque regional considera que el origen regional es un factor importante en las prácticas económicas y políticas de los empresarios mexicanos. El segundo da mayor peso al origen histórico y a las condiciones de surgimiento para establecer la configuración definitiva, las prácticas económicas y políticas predominantes y los patrones de desarrollo de los grupos. El tercer enfoque de las estrategias corporativas y organizacionales, atiende la cambiante estructura organizativa de las grandes corporaciones modernas y su tendencia a adoptar estructuras de administración y morfologías corporativas más complejas. Se establece el método comparativo para tener en cuenta aquellas situaciones en que las características comunes de las empresas se combinan con circunstancias históricas que preceden a la formación de grandes corporativos de Monterrey.
Pérez-Sánchez B., Guzmán-Sala A., Mayo-Castro A., Heredia-Mateos R.H. Historical development of cementos mexicanos: An economic group with national capital. Hitos de Ciencias Económico Administrativas 2013;19 (55): 115-130.

\section{ABSTRACT}

Objective: To know the historical evolution of a large company that runs with national capital and approach the strategies that this firm has implemented in order to become a major corporate or economic group. The first approach has to be with the historical evolution where the origins and development of the firm prevail. Because of this, the chronicle and descriptions predominate. It gathers events of the national life and the local life in Monterrey, with the guidance of a chronological order, achieving the establishment of analytical approaches.

Material and method: The methods used were the historical-critical method, the analytical method with a dynamic approach, and the comparative method. The approaches used were: 1) the regional, 2) the historical origin, and 3 ) the corporate strategies and organizations. The regional approach considers that the regional origin is an important factor in the economic and political practices of the Mexican entrepreneurs. The second approach gives more weight to the one of historical origin and the conditions of emergence to establish the definite configuration, the predominant economic and political practices, and the patterns of group development. The third approach, the one of corporate and organizational strategies, responds to the changing organizational structure of large modern corporations and their tendency to adopt managerial structures and more complex corporate morphologies. The comparative method is established to take into account those situations where the common characteristics of the companies are combined with historical circumstances that precede the formation of large corporates in Monterrey.

*Doctora en Economía. Profesora-Investigadora. División Académica de Ciencias Económico Administrativas (DACEA). Universidad Juárez Autónoma de Tabasco (UJAT).

** Doctor en Economía. Profesor-Investigador. DACEA-UJAT.

*** Doctor en Finanzas Públicas. Profesor-Investigador. DACEA-UJAT.

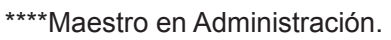

Fecha de recibido: 7 de noviembre de 2012 Fecha de aceptación: 14 de diciembre de 2012. 
Resultados: No se pretendió hacer un análisis histórico profundo, sino identificar y reconocer los eventos históricos y particularidades del comportamiento empresarial en Monterrey a fin de rescatar una presencia socioeconómica activa que llevará a considerar el surgimiento de un gran corporativo o grupo económico que ha transitado a la lógica nacional. Se abordó a Cementos Mexicanos desde su constitución como empresa en 1906 hasta 1982. Al periodo comprendido entre 1890 y 1910 se le puede considerar como la etapa de surgimiento de las grandes empresas manufactureras en México, período que corresponde al porfiriato. El patrón de inversiones que predominó dio como resultado una gran concentración del capital en los sectores de ferrocarriles, minería y banca, aunque también en algunas empresas del sector industrial como Cementos Hidalgo (hoy Cementos Mexicanos, S.A.). En Monterrey surgieron en esa época grandes empresas que todavía subsisten y son la base de varios grupos o corporativos industriales actuales.

Conclusiones: El nacimiento industrial de Monterrey, es el resultado lógico de un proceso de acumulación de capital dentro del ámbito comercial y de la necesidad de esos capitales de hallar nuevos campos de aplicación que posteriormente invirtieron en la esfera industrial. Los factores a los que podemos atribuir el desarrollo industrial de Monterrey corresponden al apoyo permanente del Estado, a factores geográficos favorecedores y a coyunturas históricas de México. Una segunda etapa de periodización de las grandes empresas se localiza en los años que van de 1930 a 1950 y se caracteriza por la instalación de empresas dedicadas a sustituir importaciones y la producción orientada hacia un mercado nacional y donde el Estado orientó el proceso de desarrollo. Entre los antecedentes históricos de estas empresas encontramos que en 1931 se fusionaron Cementos Hidalgo y Cementos Portland Monterrey y formaron Cementos Mexicanos, S. A. En una tercera etapa que va de 1951 a 1970 se da propiamente el surgimiento del grupo económico de Cementos Mexicanos cuando sus inversiones se dirigen hacia la integración tanto horizontal como vertical y la diversificación en la producción de las empresas, así como la suscripción en la Bolsa de Valores.
Results: It was not intended to do a deep historical analysis, but to identify and recognize the historical events and special particularities of the entrepreneurial behavior in Monterrey in order to rescue an active socio-economic presence that will lead to consider the emergence of a great corporate or economic group that has transited to the national logic. Cementos Mexicanos was addressed since it was constituted as a company in 1906 until 1982. The period between 1890 and 1910 can be considered as the stage of emergence of the great manufacturing companies in Mexico, and this period corresponds to the Porfiriato. The predominant pattern of investments resulted in a great concentration of the capital in the railway, mining and banking sectors, but also in some companies of the industrial sector such as Cementos Hidalgo (nowadays Cementos Mexicanos, SA). In Monterrey at that time, large companies emerged and they still exist and are the basis of several existing industrial corporate groups.

Conclusions: The industrial birth of Monterrey is the logical result of a process of accumulation of capital within the commercial scope and the need of those capitals to find new fields of application that subsequently were invested in the industrial sphere. The factors that can be attributed to the industrial development of Monterrey correspond to the permanent support of the state, the geographical favourable factors, and the historical junctures of Mexico. A second stage of periodization of the large companies is between the years 1930 and 1950 and it's characterized by the establishment of companies devoted to substitute importations and to the production oriented towards a national market where the state oriented the process of development. Among the historical background of these companies it was found that in 1931 «Cementos Hidalgo» and "Cementos Portland Monterrey» merged and they formed the firm "Cementos Mexicanos, S. A.» In a third stage, that goes from 1951 to 1970 , the emergence of the economic group «Cementos Mexicanos» was actually given, when its investments were directed towards both, not only the horizontal integration but also the vertical one and the diversification in the production of the companies, as well as the subscription in the stock market.
Palabras clave: Corporativos. Grandes empresas. Grupo económico. Industria cementera. Integración vertical. Historia económica.
Key words: Corporate. Corporations. Economic group. Cement industry. Vertical integration. Economic history.

DIRECCIÓN PARA RECIBIR CORRESPONDENCIA: Correo electrónico: betyperez10@hotmail.com 
a historia es el ámbito de conexión entre el individuo y la sociedad en términos de una práctica concreta. Se distingue un tipo de historia, un tiempo de ritmos lentos pero perceptibles, la historia social, la historia de grupos y agrupaciones (Meyenberg, 1993, pp. 91-99). En la historia de la empresa se considera que el cambio es continuo, de carácter recíproco y ritmo variable, se piensa que los empresarios, junto con otros individuos y grupos dentro de la sociedad han contribuido a provocar cambios en su medio, tanto dentro como fuera de las propias instituciones (Hidy, 1977, pp. 446-447).

Por ello, es pertinente centrarse en los empresarios en cuanto a responsables de las decisiones y en cuanto a constructores y destructores de instituciones, así como en las ideas y conocimiento acumulado que influyen el lugar, tiempo y gestión de las actividades empresariales, también y sobretodo en el desarrollo de las empresas en cuanto instituciones de carácter e impacto económico, vislumbrar el desafío que las zonas no desarrolladas y subdesarrolladas plantean a la empresa privada.

El grupo burgués regiomontano transitó por un proceso de acumulación originaria de capital, su actividad cotidiana condicionada por el momento histórico le permitió una concentración de dinero y de bienes, antes de transformarse en controlador directo de actividades productivas, tendiendo a transformarse en clase social justamente cuando inició su traslado masivo de capitales a la producción capitalista (Cerutti, 1992, p.133) a partir de 1890 en un movimiento que usufructuó las condiciones generadas por el porfiriato, las nuevas vinculaciones que se planteaban con la economía internacional y la estructuración y ampliación del mercado interior y la producción en gran escala de bienes dedicados al propio proceso productivo, con base en la industria pesada (Ibid, 136).

\section{El marco corporativo en la época de la Colonia}

La historia de Monterrey, como parte de la historia nacional, refleja en lo general el devenir histórico de la misma. No obstante Monterrey presenta ciertas peculiaridades. En esta época Monterrey fundada en 1596, fue un punto perdido durante varios siglos en la vasta geografía de Nueva España. De hecho, en el esquema general de gobierno y colonización españoles, las provincias norteñas de Nueva España ocupaban una posición marginal. Con unas pocas excepciones notables, carecían de la fuerte vida urbana que se daba en el centro. Con una escasa población desperdigada en las vastas áreas de un territorio árido, montañoso y hostil, las zonas norteñas quedaban separadas del centro no sólo por factores geográficos, sino también por estructuras sociales y étnicas distintas.

El norte económicamente fue dominado desde la Colonia por la minería, las haciendas ganaderas y la agricultura extensiva, actividades que se hallaban íntimamente ligadas; varias haciendas inmensas se desarrollaron con base en las utilidades de la minería o bien fueron proveedores de víveres, pieles y materia prima para los centros mineros. Era notable tanto la ausencia de una población indígena sedentaria habituada al trabajo agrícola, típico del centro y del sur, como los rasgos de una colonización predominantemente española y mestiza. Sin embargo, el norte tuvo un problema indígena, las incursiones en oleadas de los indios nómadas fueron un factor básico para desalentar la colonización en gran escala de la región. La escasez general de mano de obra que no resolvieron los fallidos intentos de colonización, suavizaron e incluso hicieron desaparecer instituciones como el peonaje. Al mismo tiempo, los grandes espacios y el aislamiento favorecieron y facilitaron la supervivencia de algunas instituciones semifeudales, como los ejércitos privados y la aplicación de justicia por particulares, que mucho tiempo después de que se hubiera alcanzado la independencia aún existían.

El bastión del poder colonial español, la Iglesia católica, tuvo un papel secundario, mínimo, en las provincias norteñas, especialmente en el campo económico. Las tierras estaban casi exclusivamente en manos seculares y no había parroquias y conventos ricos o grandes propiedades eclesiásticas como en el sur. Esta presencia relativamente discreta de la Iglesia, tendría un importante efecto sobre los acontecimientos que siguieron a la independencia. No pudo repetirse en el norte la alianza conservadora entre una población indígena cuasi servil y la Iglesia, como sucedió en el centro; este factor ayuda bastante, a explicar la devoción a la causa del liberalismo en la región, a lo largo del siglo XIX (Carr, 1973, pp. 322- 323).

En Monterrey desde la época de la colonización se encuentran factores que explican su devenir, entre ellos es posible mencionar: 1) la lejanía respecto a la ciudad de México como centro político nacional; 2) librar la llamada guerra viva, es decir la expulsión del bárbaro de sus solares y su posterior exterminio emprendida contra las naciones indígenas nómadas en el norte; 3 ) la precariedad de las vías de comunicación que volvía muy difícil el contacto entre los distintos territorios y regiones del país. Estos factores provocaron y tal vez obligaron a que sus moradores buscaran a toda costa su supervivencia por medios propios, propiciando una forma de colonización distinta en cierto modo a la desarrollada en el centro, sur y sureste del país (Espinosa, 2007, pp.90-91). 


\section{La Independencia de México: reorganización industrial}

La insurrección popular de 1810, el proceso de emancipación de México, implicó la desarticulación del sistema económico preexistente, en parte como consecuencia de las acciones bélicas y la ruptura con España. Era necesario para México que su excedente económico se quedara en el país para crear las condiciones de una acumulación originaria de capital (Marx, 1975, pp. 942-943), dado que en la realidad el excedente económico fluía hacia el exterior para convertirse allá en capital, por ende autores como Enrique Semo afirman que en México lo que se dio fue una «desacumulación originaria» (Semo, 1973, pp. 232-236).

La estructura económico-social heredada del periodo colonial se caracterizó por un bajísimo nivel de desarrollo de las fuerzas productivas y por relaciones sociales de producción basadas en la servidumbre y la esclavitud. Con la independencia se desató un complejo proceso de cambio que siguió direcciones opuestas; de una parte se fortalecieron formas de producción no capitalistas; de otra, se desplegaron ciertas formas de producción capitalista. De hecho se dio un proceso de polarización en el que se mantuvo durante largo tiempo un equilibrio inestable entre sus diversas dominaciones, pero que halló su desenlace en la revolución de Reforma. Fue, así un periodo de transición de la sociedad colonial (no-capitalista) a la sociedad neo-colonial (capitalista dependiente) (Leal, 1972, p. 6).

Monterrey hasta 1850, por una parte, no había reunido las condiciones que llevaron a destacar a otros estados de la república durante la etapa colonial, cuando se compara con zonas como Guanajuato o Zacatecas, puesto que no fue ni tuvo en su entorno inmediato un centro minero de elevada significación, o como Veracruz que asumió la condición de puerto oceánico o fluvial, no fue capital virreinal como la ciudad de México, no operó como eje de distribución mercantil internacional o intracolonial, ni como pivote de regiones con producción semi manufacturera como Guadalajara o Puebla (Cerutti, 2000, p. 19). La historia económica reciente señala como hito transformador del noreste la redefinición de la frontera norte de México, que fue resultado de la guerra contra Estados Unidos entre 1846 y 1847. Este hecho desencadenó un proceso comercial y económico; provocó un reordenamiento del espacio regional alrededor del bajo río Bravo en las décadas posteriores al episodio bélico, un entorno regional-binacional que se extenderá más allá de las fronteras propiamente nacionales de ambos países. De tal forma Coahuila, Nuevo León y Tamaulipas, en el gran norte oriental mexicano y Texas, como parte de Estados Unidos se articularon bajo una dinámica neoeconómica que propició condiciones políticas, económicas e históricas únicas no sólo respecto al resto de México, sino incluso a Latinoamérica. Luego de la invasión estadounidense y el acercamiento de la frontera norte, se presentó otro acontecimiento que favorecía el comercio e intercambio económico en el noreste: la guerra de Secesión en Estados Unidos entre 1861 y 1865. Este hecho permitió las condiciones para el «tráfico ilícito» de mercancías y el estímulo para la acumulación de capital (Fuentes, 1976, pp. 44-50).

\section{El porfiriato: surgimiento de grandes empresas}

El capital y el capitalismo como sistema productivo fueron los que tendieron a imponer su hegemonía a la política económica que caracterizó al porfiriato. Una política que intentó saturar amplios espacios del Estado-Nación que se afirmaba. Los núcleos burgueses - dueños del capital, gestores del capitalismo-fueron los que dieron sustento a la política global de crecimiento económico que Díaz propició, en estrecha alianza con el inversionista extranjero que traía recursos, tecnología, fuerza de trabajo especializada y una forma de organización empresarial que echó raíces en el país.

Entre 1870 y 1910 se multiplicaron las grandes empresas modernas, distintos procesos operaron al mismo tiempo: 1) La ampliación de los mercados regionales y el creciente proceso de vinculación entre los mismos; 2) Las nuevas corrientes de inversiones extranjeras desde el decenio de 1880; 3) El desarrollo de mercados de capitales locales; y 4) La creación de nuevos marcos institucionales para las actividades económicas. Todos estos procesos contribuyeron al nuevo panorama que permitiría una aceleración del desarrollo capitalista en el país.

Entre las primeras grandes empresas modernas establecidas en México en el último cuarto siglo del $\mathrm{XIX}$ es frecuente citar en orden de prioridad a las compañías ferroviarias ya que eran las mayores compañías del porfiriato en términos de capitales y también en volumen y extensión de actividad. En su mayoría estas compañías nacieron grandes y desde un principio, adoptaron modos organizativos que eran similares a sus contemporáneas en los Estados Unidos, por ejemplo nos referimos en particular al Ferrocarril Central (1880) y el Ferrocarril Nacional (1882) que crearon las primeras redes de transporte moderno en el centro-norte del país. Distinto es el caso del Ferrocarril Mexicano (1873) que conectaba el puerto de Veracruz con la ciudad de México, financiado en parte con capital británico y en parte con capitales locales (Marichal, 1997, pp. 25-26). 
Nuevas condiciones en la minería, las comunicaciones y la propiedad de la tierra, alteraron la evolución del norte de México. El aspecto más impresionante fue sin duda el crecimiento de la gran propiedad en toda la República. La legislación agraria de la reforma liberal de 1856-1857, había empezado el proceso al transferir a manos privadas vastas propiedades eclesiásticas y corporativas, la enajenación de los terrenos baldíos por el Estado y por medios privados, la de las tierras comunales de los indios (Carr, 1973, p. 323). La zona norte que nos ocupa, registró un importante crecimiento económico. La extensión de los ferrocarriles favoreció la minería en gran escala $(42.39 \%$ de la producción nacional en 1907) y la producción agropecuaria en grandes extensiones y utilizando métodos modernos de cultivo. En 1908, las fábricas y talleres regiomontanos generaron valores superiores en casi nueve veces a los registrados en la agricultura, una de las tradicionales bases productivas de Nuevo León. En 1910, el agro alcanzó sólo el $19 \%$ de los valores gestados por la metalurgia pesada y la siderurgia, que ya funcionaban en Monterrey (Cerutti, 1982, p. 81). Por ende, el dato vertebral que caracterizó a Monterrey, no fueron las fábricas de bienes ligeros y de consumo masivo, sino la producción de bienes e insumos destinados a la misma producción (Cerutti y Valdaliso, 2003, p. 81).

La acumulación de capital de la burguesía porfiriana provino, fundamentalmente, del gran comercio legal e ilegal, del agio practicado por los grandes comerciantes, del acaparamiento de las propiedades urbanas y rurales que pasaron del clero a manos privadas con las Leyes de Reforma y las de Baldíos, de las actividades agrícolas y ganaderas en gran escala y de la agroindustria. Los empresarios regiomontanos, gracias al aislamiento geográfico en relación al centro político de la nación, su relación con la economía fronteriza de Texas y la construcción del poder regional del gobernador de Nuevo León (y de Coahuila, estado que anexo en 1856) Santiago Vidaurri, favorecieron el surgimiento de un grupo de familias que acapararon el comercio legal y de contrabando, llegando a acumular enormes fortunas bajo el siguiente proceso:

1. La primera fase de este proceso se inició con la definición de la nueva frontera septentrional de la república derivada de la guerra de 1847 con Estados Unidos. Los comerciantes de Monterrey aprovecharon esta coyuntura que, junto con el reordenamiento político-militar de la región encabezado por Vidaurri (1855-1864), les brindó oportunidades excepcionales para enriquecerse.

2. La guerra de Reforma fue el escenario en que se aceleró este proceso, gracias a la demanda de alimentos y pertrechos militares que fueron satisfechos por los mercaderes locales.

3. Adicionalmente, una serie de medidas fiscales implantadas por el gobernador que privaron a la federación de sus ingresos tradicionales y los transfirieron al gobierno local a fin de financiar al ejército y fortalecer su autonomía, propiciaron la reproducción del comercio regional y con el sur de Estados Unidos:

- $\quad$ Tanto los aranceles como los impuestos a la circulación y exportación de metálico (plata y oro) fueron recaudados y manejados por el gobierno local, acrecentando el circulante. Como contrapartida se esforzó por ofrecer al tráfico mercantil -especialmente al que conectaba con el exterior- la protección necesaria ante el peligro indígena, el asedio de grupos de bandoleros, las amenazas de ejércitos oponentes y la voracidad fiscal de los gobiernos «del centro».

- Los descuentos ofrecidos por el arancel Vidaurri (1855), el establecimiento de una serie de puestos aduanales en la margen sur del río Bravo y los préstamos voluntarios o forzosos con altos intereses que los negociantes locales proporcionaban para la manutención del ejército, y que eran cubiertos con certificados deducibles de los impuestos de importación, impulsaron el desarrollo de un reducido núcleo de comerciantes asentados en la capital neoleonesa y en Coahuila.

- Los regiomontanos competían ventajosamente con los mercaderes de Veracruz y la capital, pues el arancel Vidaurri estableció derechos de importación que llegaron a ser hasta $60 \%$ más bajo que el federal, de suerte que pudieron ampliar el ámbito de su mercado (Cerutti, 1992, pp. 32-60).

4. La formación de estos primeros grandes capitales se vio favorecida también por el estallido de la guerra de Secesión, durante la cual el algodón y los pertrechos de guerra del sur estadounidense fueron comercializados en el noreste mexicano, al tiempo que se incentivó la producción agropecuaria local gracias a la creciente demanda de los plantadores (Ibid, pp. 74-75).

Es así que la acumulación del capital comercial y la apropiación de vastas extensiones de tierras por parte de la oligarquía regiomontana, que posteriormente invirtió en la esfera industrial, nació ligada al poder regional de Vidaurri; ambos formaron una mancuerna 
mutuamente redituable (Collado, 2004, p. 51). Monterrey se convierte en centro de un intercambio que desborda no sólo Nuevo León, sino el propio noreste, dada su ubicación semifronteriza, próxima a puertos que crecen en significación como Matamoros y Tampico, pero que será reafirmada por las políticas de Santiago Vidaurri.

Entre 1890 y 1910 se da una muy marcada diversificación de las inversiones que pusieron en marcha tanto industrias dedicadas a abastecer el consumo productivo (grandes fundiciones, cemento, vidrio) como el consumo personal (cerveza y otras bebidas, textiles, artículos para higiene, materiales para la construcción, alimentos elaborados), el ramo minero, el crédito y los bancos, la propiedad y explotación de la tierra, los servicios y el transporte.

Cementos Hidalgo S. A. fundada en 1906, es el origen de Cemex. Esta empresa fue creada en Gómez Palacio el 3 de febrero de 1906, pero comenzó a operar en diciembre de 1907 en San Nicolás Hidalgo, Nuevo León, a unos cuarenta kilómetros al norte de Monterrey. Aunque gestada desde la comarca lagunera, la planta fue construida en las cercanías de Monterrey por la gran riqueza de los yacimientos bien ubicados, por otro lado respecto a la red ferroviaria. Los accionistas y junta directiva reflejaron la combinación de capitales provenientes de Chihuahua, La Laguna, Monterrey yen su caso, de la ciudad de Durango. El capital de arranque sumó 500 mil pesos, hacia 1911 había aumentado a un millón y medio. Esta rápida triplicación del capital se debió a la velocidad con que Cementos Hidalgo entró en el mercado nacional y a la correspondiente ampliación de su capacidad productiva.

El cemento era un producto de reciente aplicación a escala internacional. Aunque con antecedentes en la primera mitad del XIX, este material -en versión Pórtland- fue incorporado masivamente a las labores de edificación a fines de siglo. En ese momento la revolución del concreto llegó a México. Por lo tanto, la cementera encontraba un mercado en expansión ilimitada. En 1909 al habilitarse el horno rotatorio 2, quedó más que duplicada su capacidad de producción hasta alcanzar 66,000 toneladas de cemento anuales. Frente a los 25 mil de 1907. En vísperas de la revolución, con nuevos hornos, volvió a duplicarse. La cementera se definió como una de las principales del país ante la entrada casi constante de cemento europeo y estadounidense (Cerutti, 2000, pp. 97-98).

\section{Época revolucionaria: paralización empresarial}

La historiografía ortodoxa (Collado, 2004, p. 51) concibió al porfiriato como un régimen autoritario, opresivo y extranjerizante, y contempló al movimiento armado que dio inicio en 1910 como una auténtica revolución social con contenido de clase, caracterizándola como popular, agraria y espontánea, por lo cual condujo a una violenta confrontación entre los campesinos y los terratenientes. Desde esta perspectiva, el régimen surgido de la Revolución representó un cambio radical por su carácter reformista, nacionalista, un cambio sustantivo en comparación con el porfiriato. También existe consenso en que el despegue definitivo del capitalismo se inició durante el porfiriato, que fue durante ese periodo cuando se consolidó propiamente la burguesía como clase social (González, 1961, p. 636) y que la revolución no destruyó totalmente el aparato productivo (Collado, 2004, p. 55).

De acuerdo con Basave (2001) la violencia, inestabilidad política y destrucción física que prevaleció durante la Revolución frenó el proceso de inversión de los grupos empresariales y con escasas excepciones prácticamente se canceló toda nueva inversión entre 1910 y la primera mitad de los años veinte. La lucha armada influyó poderosamente en el deterioro de la economía en su conjunto, la producción en los sectores minero y agropecuario decreció en más de $40 \%$ y el sector industrial lo hizo en $25 \%$ (Hernández, 1985). No obstante, la revolución encontró a la burguesía regiomontana con el poder y solidez socioeconómica suficiente como para capear los problemas que desató la propia revolución. El sustento industrial de este empresariado le permitió mantener a mediano plazo condiciones suficientes para su reproducción capitalista, aún cuando el hecho de que muchos burgueses fuesen terratenientes afectados por la caída de Porfirio Díaz (Cerutti, 1992, p. 136). En el momento de la Revolución, Monterrey era la cuarta ciudad del país y ocupaba idéntico puesto en lo que atañe a la tasa de crecimiento anual de población (3.7\%) en urbes con más de 25 mil habitantes en el periodo 1895-1910. El crecimiento poblacional de Monterrey se acompañó además por las migraciones desde estados vecinos y cercanos. La mayoría provenía de San Luís Potosí, Coahuila, Durango, Tamaulipas, Zacatecas, Guadalajara y Aguascalientes. En 1900, el 33\% de los habitantes de la ciudad eran originarios de otros estados (Cerutti, 1986, pp. 23-24).

En 1912 Cementos Hidalgo suspende la producción, la falta de energía eléctrica, vías de comunicación y recursos humanos previene que la compañía continúe su distribución de cemento. En 1913 comenzó a sentir el impacto del conflicto en un doble sentido: porque las primeras partidas armadas, aunque todavía pequeñas, empezaron a asediarla y porque el sistema ferroviario resentía ya de manera visible las consecuencias de la guerra civil. La producción, momentáneamente paralizada, se reinició con dificultades. No obstante, 
en marzo de 1914 cuando Monclova fue atacada y las comunicaciones quedaron seriamente lastimadas, se clausuró la actividad en forma definitiva. El 14 de octubre de 1914 Cementos Hidalgo fue confiscada; la orden la impartió el general Antonio Villarreal, gobernador de Nuevo León y jefe de fuerzas carrancistas.

El fin del conflicto armado trajo consigo la refundación del Estado mexicano: Carranza emprende los primeros trabajos para organizar un régimen de instituciones, instituye el orden jurídico-político al promulgar la Constitución de 1917. En su artículo 27, la constitución concede expresamente al Estado revolucionario el poder de fundar y regular las relaciones de propiedad para que lleve a efecto las reformas sociales $y$, en primer término, la reforma agraria; pero al mismo tiempo ese poder aparece como la facultad ilimitada de organizar y dirigir el desarrollo económico del país. Reconoce y define el régimen de propiedad mediante tres modalidades: la propiedad privada, la propiedad pública y la propiedad social.

\section{Los años veinte}

El periodo posrevolucionario de 1921 a 1930 fue de esfuerzos institucionales para convertir el país de minero, petrolero y agropecuario, en un país en proceso de industrialización. En la edificación del nuevo orden de los difíciles años veinte asumió la presidencia Álvaro Obregón (1920-1924), quién empezó por aplicar la reforma agraria, consolidó las organizaciones obreras, expropió latifundios, creó el Banco Único (1923) e impulsó la educación. Durante el gobierno del presidente Plutarco Elías Calles (19241928) se encuentra la creación del Banco de México (31 de agosto de 1925) y con ello la intervención más directa en el desenvolvimiento de las operaciones económicas, financieras, monetarias y crediticias. Calles instauró una mayor precisión en las políticas económicas y de reconstrucción, y muchas empresas de Monterrey lograron restablecer su ritmo a mediados de la década, el caso más conocido es el de Fundidora de Fierro y Acero.

Es importante señalar de acuerdo con Basave (2001) que durante los años veinte, el capital estadounidense por su parte había logrado controlar de nuevo importantes inversiones. Fue un periodo de instalación de filiales de grandes trasnacionales en territorio nacional (fenómeno que volvería a presentarse con posterioridad a la segunda guerra mundial). No obstante, que la mayoría de los sectores económicos permanecieron estancados, algunos sectores manufactureros tradicionales como alimentos y textiles, así como la producción de hierro, acero y cemento mostraron una rápida recuperación (Hansen, 1978, p. 43). La reconstrucción económica señala, Cerutti
(2000): «procuraba desenvolverse mientras los grupos de poder gestados por la revolución proseguían su lucha por el control del Estado, cuando arreciaba la caída de la producción y exportación del petróleo, y cuando México empezó a resentir desde 1926 un nuevo descenso, en los precios de la plata». La recuperación de mediados de los años veinte sugiere que algunos empresarios de Monterrey lograron consolidarse financieramente e iniciar una primera etapa de expansión, así como fundar nuevas empresas.

En la historia de Cemex, se observa crecimiento y expansión en esta etapa de reconstrucción nacional: en 1920 Cementos Pórtland Monterrey inicia operaciones con una capacidad de producción anual de 20,000 toneladas. El primer horno de la planta de tipo largo de un solo paso y de proceso seco, utiliza la tecnología más moderna de su época. La planta comercializa la marca Cemento Pórtland Monterrey para satisfacer la demanda del noroeste de México. En 1921, reanuda su producción total en la planta Cementos Hidalgo.

\section{Los años treinta: la tendencia a la integración industrial}

Durante la década de los treinta, el papel del Estado en la economía se había ampliado considerablemente, esta expansión trajo aparejado conflictos con el sector exportador que para entonces se encontraba controlado casi en su totalidad por intereses extranjeros. Estos conflictos llegaron al grado máximo durante los días de la nacionalización petrolera del presidente Cárdenas en 1938. En ese mismo periodo la creciente influencia del Estado en la economía causaba tensiones considerables con los empresarios de Monterrey, quienes estaban completamente identificados con la ideología del mercado libre y la economía de la libre empresa (Vellinga, 1988, p. 40). La formación de un nuevo Estado obligó al empresariado de Monterrey aceptar una más resuelta intervención gubernamental en la esfera socioeconómica. Entre las respuestas de este empresariado de raíces porfirianas cabe señalar: a) el desenvolvimiento de un sindicalismo local dependiente de las propias empresas (sindicalismo blanco); b) la organización de la Confederación Patronal de la República Mexicana (COPARMEX), en 1929 y que serviría de contrapeso a organizaciones empresariales más próximas al poder federal y más propenso a subordinarse al nuevo orden (Periódico Oficial de la Federación, Nuevo León).

No obstante, en términos económicos los empresarios regiomontanos recibieron apoyo del Estado; cabe señalar que a fines de 1927 el gobernador Aarón Sáenz expidió una nueva legislación para fomento de la industria, ampliando los estímulos y garantías ofrecidos en tiempos de Bernardo Reyes. En 1927 el gobierno 
del estado de Nuevo León profundizó una legislación existente desde 1888, la Ley sobre Protección a la Industria, favorable al capital y al específico desarrollo industrial, ley que se anticipó con claridad a las que a escala nacional se sancionarían en los años treinta y cuarenta. Este ordenamiento declara el fomento industrial como de "utilidad pública» usando una expresión que ya había aplicado Bernardo Reyes. A diferencia de los decretos anteriores, las franquicias se otorgaban no sólo a industrias nuevas sino también a aquellas que ampliaban su tamaño, capital o número de trabajadores. Se concedían hasta por veinte años, eximiendo el $75 \%$ de los impuestos estatales y municipales. Una nueva legislación también los favoreció, la Ley sobre Franquicias a la Constitución de Nuevas Sociedades Anónimas (Periódico Oficial de la Federación). Esta Ley beneficiaba exclusivamente a las sociedades industriales o las que fomentaran la industria en Nuevo León y eximía del pago del $75 \%$ de los derechos de inscripción (en el Registro Público de la Propiedad) a los inmuebles en que se montara la fábrica o el organismo de fomento industrial.

Gracias a esta legislación la expansión que se manifestó a partir de mediados de los treinta, incluyendo modalidades que se acentuarían en la década de los cuarenta, influenció: 1) La tendencia a la integración industrial; 2) La puesta en marcha de plantas productivas en diferentes lugares del país y en algunos casos en el exterior. A esta integración industrial se le conoció, como empresas-madre, posteriormente holding (y los grupos que impulsaron) intensificaron su ciclo de adaptación al nuevo régimen político, superando la crisis de1929 y comenzaron a usufructuar el aparato de protección, subsidios, concesiones, créditos y consumo dirigido que permitía un Estado dedicado a estimular la industrialización de México (Cerutti, 2000, p. 159). El caso más conocido y popular fue Cervecería Cuauhtémoc, que desde 1921 comenzó a transformar sus departamentos internos en empresas autónomas.

Entre los antecedentes históricos de esta década, Cemex registra que en 1931 se fusionaron Cementos Hidalgo y Cementos Pórtland Monterrey y formaron Cementos Mexicanos, S. A., CEMEX. Desde 1930 con la instalación de su segundo horno en Planta Monterrey, incrementó en un $100 \%$ su capacidad de producción para satisfacer la demanda del noreste de México.

En México, los años del 30 al 40 fueron de crisis económica y financiera. No obstante, el cuerpo principal del aparato financiero establecido en Monterrey se estableció en el despegue industrial de estas décadas del treinta y cuarenta. En ese periodo se fundaron no menos de 28 instituciones financieras y de crédito. Los bancos entraron al mercado de acciones y bonos con el fin de satisfacer las necesidades de inversión de capital en la industria y el comercio regionales (Vellinga, 1988, p. 49).

Los años cuarenta y cincuenta: la sustitución de importaciones y el desarrollo estabilizador

El crecimiento hacia fuera se extiende desde la independencia hasta la gran depresión de 1933, coyuntura que marca el viraje al modelo de desarrollo hacia adentro. Más aún el viraje del modelo de desarrollo se da entre la depresión y el final de la guerra (Pinto, 1991, pp. 242-243). La coyuntura de guerra, la escasez de manufacturas importadas y la ampliación del mercado interno tornaron cada vez más necesario en México, la producción interna de bienes transformados. Entre 1940 y 1980 se dio en México un nuevo modelo económico la sustitución de importaciones que se caracterizó por tener su base en el proteccionismo económico y en la significativa participación estatal en un considerable número de ramas de la economía. El crecimiento hacia dentro depende fundamentalmente de la acumulación y del ahorro interno, dado que las actividades para el mercado doméstico no suscitan el interés de inversores como aquellas que se proyectan al exterior. En los años cuarenta, México consideró que debía industrializarse para acelerar su paso e ingresar en el conjunto de países llamados «desarrollados». El proceso de industrialización que se inició entonces requería el fortalecimiento de una industria intermedia que llevara, poco a poco, a fabricar en México todo lo que hasta ese momento se tenía que importar en el extranjero. Ese es el comienzo del proceso llamado sustitución de importaciones (Puga, 1995, pp. 2324). Llegar a ese punto implicó llevar a cabo tareas pendientes de la Revolución mexicana y convertir al Estado en el pivote del crecimiento económico. La reforma agraria cardenista, la expropiación petrolera, la nacionalización de los ferrocarriles, la creación de Nacional Financiera, del Instituto Politécnico Nacional y de otras instituciones fueron las bases que se necesitaban para dar ese impulso al proceso industrializador.

El modelo proteccionista funcionó satisfactoriamente durante varias décadas, numerosas empresas se fundaron y crecieron a lo largo del periodo. En Monterrey, la industrialización siguió esta pauta durante las décadas de los cincuenta y sesenta. Los sectores dedicados a los metales y a la metalurgia, que trabajaban a su máxima capacidad, recibieron un fuerte impulso produciendo insumos para la industria bélica norteamericana. Surgieron o se desenvolvieron así numerosas empresas ligadas a la metálica básica, los minerales no metálicos, la fabricación de productos metálicos y eléctricos, y el abastecimiento de energéticos entre otros ramos (Vellinga, 1988, p. 42). 
El crecimiento del mercado interior propició en México la evolución de la industria del cemento. Además de las fábricas que estaban localizadas en la proximidad de Monterrey y en la ciudad de México, y que datan de principios de siglo, la industria se expandió desde 1940 por todos los rincones del país. Este desarrollo fue en gran medida propiciado por el Gobierno Federal al apoyar a empresarios locales con créditos de largo plazo en el marco de la política de desarrollo regional de Manuel Ávila Camacho (1940-1946). En ese contexto, fue creada en octubre de 1943 la empresa Cementos del Norte, S.A. En ese mismo año la planta Monterrey de Cemex aumentó a 250 toneladas su capacidad diaria de producción. En 1948, Cemex logró una capacidad anual de producción de 124,000 toneladas. En 1951 con una capacidad diaria de producción de 300 toneladas, inició operaciones el cuarto horno de Planta Monterrey. En 1956 Cemex conmemoró 50 años de impulsar la industria de la construcción en México. En 1959 con la expansión de Planta Monterrey, Cemex vendió 230,420 toneladas de cemento gris y 14, 692 toneladas de cemento blanco.

En la década de los cuarenta, el acelerado crecimiento industrial experimentado en Monterrey y su área metropolitana demostró la incapacidad de las compañías de electricidad para satisfacer la creciente demanda. Fue por tal motivo que en 1944 varias empresas locales se unieron para montar en copropiedad una planta generadora destinada a suministrar energía de acuerdo con las necesidades de cada uno de los accionistas. La denominada Planta de Fuerza Eléctrica del Grupo Industrial involucró a Cervecería Cuauhtémoc (aportó 6.45\% del capital), Fábricas Monterrey, Malta, Empaques de Cartón Titán, Vidriera Monterrey, Vidrio Plano, Cristalería, Vidrios y Cristales, Hojalata y Lámina, Troqueles y Esmaltes, Keramos y Cementos Mexicanos. La planta operó inicialmente con una capacidad de $15000 \mathrm{~kW}$ y para financiar su construcción se emitieron obligaciones hipotecarias por 8 millones de pesos, conjunta y solidariamente por todas las empresas copropietarias. En 1950 aumentó su capacidad a 29800 kW y en 1953 a $44500 \mathrm{~kW}$.

Los empresarios de Monterrey se dieron a la tarea de procurar energéticos de vital importancia, es el caso de la puesta en marcha en 1947 de la empresa Gas Industrial de Monterrey, S.A., constituida para tender un segundo gasoducto desde Texas, cuyo objetivo era abastecer la planta fabril de la ciudad. La inversión inicial fue de dos millones de pesos. Participaron las siguientes empresas accionistas: Malta, S.A., Fundidora de Fiero y Acero de Monterrey, Fábrica de Ladrillos Industriales y Refractarios, Cervecería Cuauhtémoc, Vidrio Plano, Vidriera Monterrey, Hojalata y Lámina (HYLSA) Troqueles y Esmaltes, Fabricación de Máquinas, Keramos, Vidrios y Cristales, Cristalería, Fábricas de Monterrey, Empaques de Cartón Titán y Cemex (Cerutti, 2000, pp. 163-164).

No obstante, en México, la industria nacional pese a sus esfuerzos no logró instaurar un crecimiento hacia dentro, la sustitución de importaciones no había sido planeada adecuadamente para operar como un todo en cada una de sus etapas, por consiguiente el modelo entró en crisis. Empezó a surgir una nueva forma de acumulación que buscó cambiar la relación entre el Estado, el capital nacional y el capital extranjero, cuyo eje pasó de ser el comercio exterior a ser la producción de bienes de consumo, el modelo se conoció como el desarrollo estabilizador cuyo pilar fue el crecimiento de la producción estatal (Basañez, 1991, pp. 169-170).

\section{Los sesenta: maduración industrial y financiera}

Eldesarrolloestabilizadormantuvoen suscaracterísticas generales las premisas de la primera década de la industrialización, pero las reforzó a partir del establecimiento de un tipo de cambio estable, de una política muy favorable al capital privado, y de una actitud de apoyo restringido a la inversión extranjera que permitió el establecimiento de numerosas empresas de capital mixto, las cuales al contar con una parte de capital mexicano se beneficiaban de la protección que el gobierno brindaba a las empresas nacionales (Baena, 2005, p. 18). Promovida por el gobierno de Kennedy en Estados Unidos, al amparo de la Alianza para el Progreso los capitales extranjeros fluyeron a México e impulsaron el crecimiento de las manufacturas. En este periodo las grandes corporaciones transnacionales fincaron sus sucursales en nuestro país.

Una vez establecida la estructura productiva de Cemex, la industria cementera creció a una capacidad total de producción de 1.5 millones de toneladas en 1943 a 3.5 millones de toneladas en 1960. Durante la década de los sesenta se concluyó la cobertura de todo el territorio al aparecer plantas en Atotonilco, Hidalgo; Torreón, Coahuila; Ciudad Valles y Taquín, San Luís Potosí y Zapotiltic, Jalisco, que pasaron luego a formar parte de Cemex. En 1960, la planta Monterrey de Cemex incrementó a 500 toneladas su capacidad diaria de producción. En 1966 Cemex inició producción en su nueva Planta Valles, que atendía a la región huasteca en México con la marca Cemento Pórtland Monterrey. Cemex adquirió la planta de Cementos Maya en Mérida y continuó satisfaciendo la demanda del sur de México con la marca Cemento Pórtland Maya. En 1967 Cemex inició la producción en su nueva planta de Cemento Torreón a través de las marcas de Cemento Pórtland Puzolana Monterrey y Cemento Pórtland Monterrey para satisfacer la creciente demanda en el noreste de 
México. En 1968 Cemex adquirió el 30\% del capital de Concretos Monterrey.

De acuerdo con Basave (1996) en cuanto al sector financiero mexicano, en los años sesenta se produjo un intenso proceso de centralización de capital que llevó a la formación de grupos financieros integrados para cubrir todos los servicios financieros que demandaba el país (bancos, financieras, aseguradoras, hipotecarias, etcétera) aunque la formalización legal de su agrupación (denominada banca múltiple) se diera algunos años después. A este proceso de fusión de bancos pequeños, que practicaron las instituciones financieras mayores, le seguió la absorción de bancos de mayor tamaño después de la segunda mitad de la década, así Financiera Serfín adquirió a Fomento de Tampico en 1971 y posteriormente al Banco de Londres y México y a Monterrey Compañía de Seguros, situándose como el tercer grupo financiero más grande del país atrás de Banamex y Bancomer. La concentración de capital también se observa en forma regional, hacia mediados de esa misma década, de acuerdo con Cordero, Santín y Tirado (Cordero, 1983, pp. 45-46) de una muestra de 639 empresas industriales de capital nacional, $60.86 \%$ se ubicaba en tan sólo tres entidades federativas: el Distrito Federal, el estado de México y el estado de Nuevo León. En esos mismos estados se localizaba también el $86.8 \%$ de las 251 empresas industriales de capital extranjero que operaban en México en el año de 1965.

Los setenta: la formación de los grupos industriales Los años 1970-1976 manifestaron con claridad los signos de agotamiento del ciclo de la industrialización protegida, afectando al sistema político y las relaciones entre el Estado, sus dirigentes y los empresarios de Monterrey. Desataron otros problemas, como la espiral inflacionaria, el endeudamiento externo, los conflictos sociales, y la devaluación de 1976. No obstante, entre 1977 y fines de 1981, México encontró una salida, cuando se dedicó a la explotación y exportación de petróleo, superando con rapidez los efectos de la devaluación de 1976. Las relaciones entre el Estado y los empresarios del norte mejoraron y una enorme inyección de recursos públicos y de créditos extranjeros brindó liquidez al mercado interior.

Por una parte, en México se dieron «líneas de crédito abiertas» para las grandes empresas. La presencia de bancos extranjeros casi se duplicó; en 1972 eran 554 bancos con registro legal y para 1979 la cifra rebasaba los 940 (Puga, 1995, p. 74). Por otra, el alza en los precios del petróleo repercutía con amplitud en México que se ubicó entre los siete países con mayor extracción del energético. La modalidad de la industrialización estaba determinada por el control hegemónico del excedente, ejercido por un bloque de actores sociales integrado por las grandes empresas nacionales, el Estado y las empresas extranjeras con inversiones en el país. Dentro del actor estatal ocupaban un lugar central la Secretaría de Hacienda y el Banco de México, mientras que del lado de las grandes empresas privadas nacionales, el papel principal correspondía a los conglomerados dominados por la banca. La articulación del Estado con las grandes empresas en general, y en particular con la gran banca, muestra que la actividad del actor público servía al objetivo de conformar y reproducir un modo hegemónico en el control del excedente, dentro de una lógica particular de la economía de mercado bajo las condiciones específicas del proteccionismo (Garrido, 2000, p. 256).

En México el proceso de industrialización y la política proteccionista del Estado orientada a impulsar la sustitución de importaciones conllevó a la formación de grupos del sector privado nacional. Las grandes empresas de Monterrey formaron grupos industriales hasta llegar a constituir grandes corporativos. Entre 1970 y la crisis de 1982 se constituyó en Monterrey en términos formales, un importante número de conglomerados, gracias a los mecanismos organizativos previos que se venían experimentando desde los años treinta y la capacidad financiera y acelerada por lo signos de agotamiento que presentaba el modelo proteccionista o sustitutivo de importaciones. En México, la práctica de inversión diversificada originada a fines del siglo XIX, se constituyó en una estrategia empresarial que buscaba compensar las limitaciones sectoriales, regionales y sociales de un mercado interior de lento crecimiento, dejando de lado la integración esencialmente vertical.

El Estado contribuyó a incentivar la reestructuración a través de estímulos fiscales que se formalizaron en la Ley de Sociedades de Fomento promulgada en junio de 1973. Esta Ley concedía subsidios para auspiciar la integración de empresas en grupos denominados unidades de fomento (Cerutti, 2000, pp. 175-176). Las dos facultades (subsidios fiscales) que otorgaba el decreto eran: a) Compensar utilidades de empresas del grupo con pérdidas de otras cumpliendo con el requisito de que las utilidades sobrantes fueran reinvertidas. Si estas utilidades eran reinvertidas en un plazo no mayor de 30 días, entonces quedaban exentas $100 \%$ del pago de los impuestos respectivos; b) Comprar acciones de empresas, invertir capital en ellas y venderlas posteriormente por medio de la Bolsa de Valores, quedando exentas totalmente de los impuestos respectivos» (Basave, 2001, p. 85).

Se alentó así, la creación de las mayores «empresas tenedoras», es decir empresas controladoras (holding) que consolidaron resultados económicos financieros 
y fiscales. La empresa «holding» tiene diferentes funciones que podríamos resumir en términos generales en: 1) permitir el control de las acciones de otra u otras empresas; 2) controlar el aspecto operacional o de coordinación de las actividades empresariales; y 3) resolver los problemas de la acción empresarial. Estas funciones pueden ser desarrolladas por la empresa al mismo tiempo o no. Existen diferentes tipos de «holding» según las necesidades de los empresarios, éstas pueden ser «holding» de grupo, personales, mixtas, etcétera (Cordero, 1997, p. 19).

En el proceso de centralización de capital que desplegaron los grandes corporativos, los objetivos fueron distintos, en algunos casos para alcanzar una mejor integración de sus procesos productivos, en otros para aumentar su control oligopólico en sus respectivos mercados lo que llevó a la compra de empresas competidoras de gran tamaño, y en varios más con el objeto de diversificarse y participar en industrias intensivas en trabajo, buscando elevar la tasa de ganancia grupal de aquellas empresas que participan tradicionalmente en industrias intensivas de capital.

Una estrategia de las grandes empresas para captar capitales es suscribirse en la Bolsa de Valores. Con la colocación de acciones en la bolsa, captan recursos de pequeños y grandes ahorradores, quienes participan así en la propiedad de las compañías. Las empresas adquieren una buena parte de su capital de esta manera y distribuyen las utilidades por medio de sus dividendos. Entre las medidas adoptadas para estimular la bolsa, encontramos que en 1975 las modificaciones a la Ley del Mercado de Valores tuvieron como propósito fusionar las bolsas de valores de México, Guadalajara y Monterrey en un organismo de carácter nacional denominado Bolsa Mexicana de Valores (Cardero, 1982, p. 174).

A partir de 1970 el volumen de las acciones en la bolsa de valores se fue incrementando aceleradamente, gracias a las modificaciones tanto de la Ley del Mercado de Valores, la Ley de Impuestos sobre la Renta y otras hechas por la Comisión Nacional de Valores (Revista Expansión, No. 257). Muchos grupos de Monterrey diversificaron de manera ostensible su base de operaciones e incursionaron con vigor en ramos como alimentos, banca, turismo y bienes raíces. Mención aparte merece Cemex quien prefirió mantener una fuerte especialización. Uno de los rasgos típicos de estos corporativos seguía siendo el fuerte predominio unifamiliar o de unas pocas familias. En casi todos los casos descendientes de las familias fundadoras y sus colegas de los años treinta y cuarenta mantenían su dirección o influían en el liderazgo, tal es el caso de Cemex. En 1976 Cemex empezó a cotizar en la Bolsa Mexicana de Valores.

En la década de los setenta a pesar de la desaceleración económica que caracterizó al periodo presidencial de Luís Echeverría Álvarez (1970-1976), Cemex logró incrementar de manera sensible su participación en el mercado nacional: llegó a sumar 3.3 millones de toneladas, equivalentes a $26 \%$ del total del país. Durante los casi 30 años que transcurrieron desde 1940, la empresa pasó de una dimensión local a multiregional. Durante los sesenta y los setenta empezaron simultáneamente a consolidare varios grupos cementeros: Cementos Mexicanos, en el mercado del noroeste; Cementos Guadalajara, en el Bajío; el grupo Tolteca, en el centro del país; el grupo Anáhuac, en el centro y Golfo de México; la San Luís Mining Company en el Pacífico, y Cementos CruzAzul, en el centro y sur del país.

\section{Crecimiento de Cemex: reestructuración,} reconversión e integración vertical y adquisiciones Entre 1970 y 1976 se manifestó un primer proceso de concentración en el que se fortalecieron particularmente dos empresas: Cementos Mexicanos que tomó el control de Cementos Guadalajara y sus plantas, y Cementos Tolteca, que se hizo cargo de la San Luis Mining y de Cementos Atoyac. En ese contexto hacia 1970 Cemex solicitó Consultoría a Crespa, McCormick \& Paget para que propusieran opciones de modernización administrativa. El resultado fue la adopción de un esquema de gestión comparable al descrito por Chandler (1996), las plantas se administrarían de manera independiente, teniendo como denominador común una estructura de soporte formada por el director general y un cuerpo de especialistas en las áreas de finanzas, mercadotecnia, relaciones y servicios técnicos, entre otros. A partir de ese momento la empresa empezó a ser conocida como: Grupo Cementos Mexicanos, S.A. Dotado de esa nueva estructura fue que el grupo inició una nueva etapa de crecimiento sin precedentes: reconvirtió su planta productiva y se integró verticalmente con empresas productoras de concreto premezclado y agregados. En México el negocio del concreto premezclado había empezado a principios de los años cincuenta. Cementos Mexicanos tuvo un primer contacto con el concreto hacia 1968 con su participación en Concretos Monterrey. En 1977 se apropió por completo de Concretos Monterrey.

La integración se aceleróluego con varias adquisiciones; para 1972, las filiales del grupo eran: Concretos Premezclados de Juárez; Concreto, Cascajo y Arena, de Torreón;Agregados Triturados de San Luís; Concreto Premezclado Garate; Concreto Premezclado Nacional, de San Luís Potosí, y su participación en Concretos Monterrey. En 1981 se adquirieron concreteras y 
empresas de agregados en León, Irapuato, Guadalajara y Mexicali. También se adquirió Productora de Bolsas de Papel, que incrementó su capacidad de producción en 1981 al inaugurar una segunda planta en Mexicali (Cerutti \& Ignacio, 2003, pp. 57-59), (ver el cuadro del grupo industrial de Cemex que muestra las empresas del grupo). Entre 1977 y 1981 se destinaron inversiones para triplicar la capacidad de producción; se inauguraron los hornos 2 de Mérida y 9 de Monterrey. En 1979 se inició la producción en los hornos 3 de Torreón y 3 de Guadalajara (todos de 430 mil toneladas anuales, con precalentador de dos etapas). Con ello el grupo alcanzó una capacidad de producción de 5.36 millones de toneladas, es decir un $63 \%$ del incremento global realizado en México. Con una nueva inversión Cemex alcanzó una producción de 8 millones de toneladas y se situó en la vanguardia tecnológica. Esta nueva inversión permitió la instalaciones de hornos F.L. Smitdth, con precalentador de cuatro etapas y que por primera vez en México, contaría con precalcinador y la instalación del horno 2 de Valles en 1981 (ver tabla I).

Los vínculos con el capital extranjero, se multiplicaron ante la nueva Ley de Inversiones Extranjeras de 1973 y los atractivos incentivos que dicha ley concedía a las empresas que tenían el mínimo requerido de capital mexicano, alentando a las empresas extranjeras a formar asociaciones con compañías y bancos mexicanos. El porcentaje requerido por la ley varió de acuerdo con el sector. En los sectores minero y de refacciones para autos, se permitía un máximo de $33 \%$ de capital extranjero y de $49 \%$ en los sectores manufactureros restantes. Aún cuando la ley no fue retroactiva, las filiales de empresas trasnacionales en México fueron alentadas a volverse jurídicamente empresas mexicanas, por medio de incentivos. Cuando no se encontraba un socio en la comunidad empresarial, Nafinsa, Somex o alguna otra agencia estatal podría completar la fracción de capital necesaria para que la filial extranjera fuera considerada jurídicamente mexicana y por lo tanto elegible para obtener los incentivos fiscales y otros subsidios aplicables. No obstante, para la década de los setenta varios mercados ya se hallaban controlados por grupos mexicanos privados que abarcaban varios tipos de industrias: 1) Aquellas en las que el capital nacional tiene el control total, como la cerveza, el vidrio, el acero, la construcción, las televisoras y las líneas áreas. El capital extranjero sólo participa por medio de licencias para el uso de tecnología; 2) Sectores en los que predominan el capital mixto (nacional y extranjero) en las compañías: papel, autopartes, petroquímica y minería; 3) Los sectores controlados por grandes empresas, nacionales, extranjeras, o mixtas, tales como el cemento, los alimentos y textiles; y 4) Aquellas en las que el capital extranjero ejerce un control completo, destacan por su importancia, la industria automotriz y de la computación. Vale la pena mencionar a las empresas Tolteca y Cemex (capital nacional) y Apasco (capital mixto) dominaron el mercado en los setenta.

TABLA I

GRUPO INDUSTRIAL CEMENTOS MEXICANOS

\begin{tabular}{|c|c|c|c|c|}
\hline \multicolumn{4}{|c|}{ Empresas industriales } & \multirow{2}{*}{$\begin{array}{l}\text { Bancos, financieras y } \\
\text { aseguradoras }\end{array}$} \\
\hline $\begin{array}{l}\text { Cementos } \\
\text { Mexicanos, } \\
\text { S.A. }\end{array}$ & $\begin{array}{l}\text { Proveedora } \\
\text { Mexicana de } \\
\text { Materiales, S.A. }\end{array}$ & $\begin{array}{l}\text { Concreto y } \\
\text { Precolado, S.A. }\end{array}$ & $\begin{array}{l}\text { Participación en } \\
\text { Concretos } \\
\text { Monterrey }\end{array}$ & \\
\hline $\begin{array}{l}\text { Cementos del } \\
\text { Norte, S.A. }\end{array}$ & $\begin{array}{l}\text { Concretos del } \\
\text { Bajío, S.A. }\end{array}$ & $\begin{array}{l}\text { Piedra Arena y } \\
\text { Jalisco, S.A. }\end{array}$ & $\begin{array}{l}\text { Concreto } \\
\text { Premezclado } \\
\text { Garate }\end{array}$ & \\
\hline $\begin{array}{l}\text { Cementos } \\
\text { Maya, S.A. }\end{array}$ & $\begin{array}{l}\text { Concreto } \\
\text { Premezclado } \\
\text { Nacional, S.A. }\end{array}$ & $\begin{array}{l}\text { Promotora de } \\
\text { California, S.A. }\end{array}$ & $\begin{array}{l}\text { Agregados } \\
\text { Triturados de San } \\
\text { Luis }\end{array}$ & \\
\hline $\begin{array}{l}\text { Cementos } \\
\text { Guadalajara, } \\
\text { S.A. }\end{array}$ & $\begin{array}{l}\text { Productora de } \\
\text { Bolsas de Papel, } \\
\text { S.A. }\end{array}$ & $\begin{array}{l}\text { Concreto y } \\
\text { Derivados, S.A. }\end{array}$ & $\begin{array}{l}\text { Fabricación de } \\
\text { Maquinaria } \\
\text { Pesada, S.A. de C.V. }\end{array}$ & $\begin{array}{l}\text { Gas Industrial } \\
\text { Monterrey, S.A. }\end{array}$ \\
\hline $\begin{array}{l}\text { Concretos } \\
\text { Cemex, S.A. }\end{array}$ & $\begin{array}{l}\text { Concretos de } \\
\text { Alta Calidad y } \\
\text { Agregados, S.A. } \\
\text { de C.V. }\end{array}$ & $\begin{array}{l}\text { Distribución y } \\
\text { Comercio de } \\
\text { Jalisco, S.A. }\end{array}$ & & \\
\hline $\begin{array}{l}\text { Concreto } \\
\text { Cascajo y } \\
\text { Arena, S.A. }\end{array}$ & $\begin{array}{l}\text { Cal } \\
\text { Guadalajara, } \\
\text { S.A. }\end{array}$ & $\begin{array}{l}\text { Concretos } \\
\text { premezclados } \\
\text { de Juárez }\end{array}$ & & \\
\hline
\end{tabular}


En términos de exportación, la aparición de México entre los países exportadores de cemento se sitúa antes de la segunda guerra, cuando se llegó a exportar hasta el $12 \%$ de la producción mundial, en 1970 sólo se traficaba el 3\% de la producción global del planeta. Entre 1976 y 1978 cuando se combinó una elevada demanda de cemento en Estados Unidos y los efectos de la política de control de precios en México permitieron que las exportaciones crecieran hasta alcanzar un millón de toneladas, y se dio como un fenómeno esporádico en Cemex y verificable en otras empresas de Monterrey (Cerutti, 2000, pp. 210222). No obstante, en comparación con los grandes grupos industriales internacionales, Cemex era a mediados del setenta una compañía muy pequeña. Su capacidad de producción equivalía al $3 \%$ de Blue Circle, al 5\% de Universal-Atlas o al 6\% de Lone Star, que ocupaban los primeros tres lugares de producción a nivel mundial.

La política federal del presidente José López Portillo previó incrementos en la planta productiva, motivados por la expectativa de un súbito aumento en el producto interno gracias al alza en los precios del petróleo. El nuevo ejecutivo estableció la Alianza para la Producción con los sectores empresariales: consistía en un compromiso mediante el cual el Gobierno Federal, los grandes industriales y la central obrera aceptaban coordinar esfuerzos con el objetivo de hacer frente a una eventual crisis de abastecimiento, en un movimiento que permitiría recuperar la confianza del capital. Fue en ese contexto que se formuló el Programa de Fomento a la Industria Cementera, en julio de 1980. El programa contenía aristas fundamentales: a) reconocía el papel estratégico de la industria del cemento; b) flexibilizaba la política de control de precios, con el fin de auspiciar la rentabilidad de las inversiones; c) brindaba garantía jurídica a los empresarios sobre la propiedad de sus reservas de materias primas, hasta entonces amenazadas de expropiación por las leyes agrarias, y d) sobre todo, se establecían mecanismos de promoción a la inversión productiva mediante la depreciación acelerada de nuevas inversiones.

En 1981 con una capacidad de producción instalada de 2,200 toneladas por día, un nuevo horno inicia operaciones en la planta Valles y para 1982 inicia producción en sus plantas Monterrey y Torreón en su décimo y cuarto horno, respectivamente. Los precalentadores de cuatro etapas y los precalcinadores de estos hornos representaron un importante avance tecnológico para la compañía al facilitar la descarbonatación de hasta un $90 \%$ de la materia prima, y una reducción en la dimensión del horno, permiten un ahorro en la instalación y refacciones. En 1982 Cemex registra la empresa Fabricación de Maquinaria Pesada, S.A. de C.V. (Revista Expansión, No. 347).
Entre 1977 y 1984 el grupo mantuvo su estrategia de generación de flujos gracias a la depreciación acelerada de sus activos, lo que le permitió ampliar su capacidad de producción con un mínimo de endeudamiento. En 1979 se invirtieron 1,155 millones de pesos en las instalaciones, de los cuales 373 provenían de reinversión de utilidades y 809 de la depreciación de los activos, por lo que el endeudamiento a largo plazo fue de sólo 399 millones de pesos. En 1980 se invirtieron 2,344 millones de pesos en las instalaciones, de los cuales 1,111 provenían de reinversión de utilidades y 2,344 de depreciación de activos: el endeudamiento no superaba los 610 millones de pesos. Por ello, al finalizar 1980 el pasivo de largo plazo contraído con instituciones como Chase Maniatan Bank of América, Crocker Nacional Bank, Citibank Nacional Association y Banca Serfín era de 2,652 millones de pesos de los cuales 508 millones eran circulante (Cerutti, 2000, pp. 186-190).

\section{CONCLUSIONES}

- En el México del siglo XVIII ya había una serie de grandes empresas excepcionales que en términos de capital, número de obreros y complejidad de organización de la producción, transporte y comercialización eran realmente importantes, aunque nos comparables con las grandes empresas modernas. Desde 1880 comenzaron a establecerse las primeras grandes empresas modernas en México: esencialmente ferrocarriles, bancos y empresas mineras, aunque también comenzaron a aparecer grandes empresas industriales a fines de siglo, gracias a la disponibilidad de capitales nacionales y especialmente extranjeros

- El fuerte sello de rasgos regionales y familiares que tuvieron los grupos económicos surgidos desde el siglo XIX hasta las postrimerías de la Revolución de 1910 puede atribuirse a diversos factores: el aislamiento de ciertas áreas, la distancia de las estructuras de poder, las desigualdades en el proceso de integración de algunas zonas geográficas. En la evolución del capitalismo tardío, es en el porfiriato donde encontramos los rudimentos de la industrialización del país, las empresas industriales que le dieron dinamismo nacieron monopólicas.

- Es válido afirmar que los empresarios participan en forma notable en la conformación de ciertas regiones como Monterrey, pero también que la región dio origen al surgimiento y consolidación de hombres de negocios con determinadas características: la clase dominante regional mediante el control de 
los recursos económicos, de la administración local y de la identidad regional, buscó expandir su base material y promover sus propios intereses haciendo compatibles algunas de las principales instituciones de la región: familia, política, empresa económica. A pesar que las regiones son dinámicas y cambian con el tiempo, en Monterrey estas características han perdurado en el tiempo.

- Una amplia porción del norte desempeñó un papel fundamental en la formación e integración del mercado nacional: a) porque el norte comenzó a especializarse en producciones para el mercado interior antes de la llegada del ferrocarril; b) por haber concentrado una vasta proporción del tendido de los ferrocarriles, que lo unían a los grandes sistemas de Texas y el resto del territorio estadounidense, c) por el efecto productivo que ocasionaron las demandas de minerales y metales de la segunda revolución industrial.

- La expansión exitosa que las empresas de Cemex lograron entre mediados de los sesenta y 1981 se explica por los siguientes factores: 1) Cemex aprovechó el crecimiento alentado por la industrialización protegida; 2) Cemex se organizó y expandió sobre la base de la ultra especialización; 3) Cemex se apoyó en un producto -el cementode larga trayectoria en la industria mexicana, con limitadísima cadena productiva y escaso valor añadido; 4) Cemex no estableció coinversiones con capitales extranjeros entre 1970 y 1981; 5) Cemex tenía a su favor estar ubicada en un mercado con gran potencial de crecimiento, sin competencia excesiva y una estructura financiera asentada, factores que explicarán su desenvolvimiento futuro.

\section{REFERENCIAS}

Baena, G. (2005). Estructura socioeconómica de México. México: Publicaciones Cultural.

Basáñez, M. (1991). La lucha por la hegemonía en México 1968-1990. México: Siglo XXI.

Basave, J. (1996). Los grupos de capital financiero en México, 1974-1995. México: El Caballito.

Basave, J. (2001). Un siglo de grupos empresariales en México, México: Porrúa.

Cardero, M., y Quijano, J. (1982). Expansión y estrangulamiento financiero 1978-1981. Revista Economía Mexicana, (4), 174.

Carr, B. (1973). Las peculiaridades del norte mexicano, 1880-1927: ensayo de interpretación. Revista Historia Mexicana, (3) 322-323.

Cerutti, M. (enero-marzo, 1982). La formación de capitales preindustriales en Monterrey (1850-1890). Las décadas previas a la configuración de una burguesía regional. Revista Mexicana de Sociología, XLIV(1), 81.

Cerutti, M. (1992). Burguesía, capitales e industria en el norte de México, Monterrey y su ámbito regional (1850-1910). México: Alianza Editorial.

Cerutti, M. (1986). Producción capitalista y articulación del empresariado en Monterrey (1890-1910). En Julio Labastida (Comp.), Grupos económicos y organizaciones Empresariales en México (23-24). México: Alianza Editorial Mexicana-UNAM.

Cerutti, M. (2000). Propietarios, empresarios y empresa en el norte de México: México: Siglo XXI.

Cerrutti, M., Ortega, I., y Palacios, L. (2000). Empresarios y empresas en el norte de México» Monterrey: del Estado oligárquico a la globalización. European Review of Latin American and Caribbean Studies 69, p. 11.

Cerutti, M., y Valdaliso, J. (abril-junio, 2003). Monterrey y Bilbao (1870-1914). Empresariado, industria y desarrollo regional en la periferia. Revista Historia Mexicana, 208(4), 909.

Cerutti, M., y Barragán, J. (2003). Cemex: del mercado interno a la empresa global en Cerutti Mario, 
(Coordinador). Del Mercado protegido al mercado global, Monterrey 1925-2000. México: Trillas.

Chandler, A. (1996). Escala y Diversificación: La dinámica del capitalismo industrial. España: Prensas universitarias de Zaragoza.

Collado, H. (enero-abril, 2004). Los empresarios y la politización de la economía entre 1876 y 1930: Un recuento historiográfico. Revista Secuencia, nueva época, (46) 57.

Cordero, S., Santín, R., y Tirado, R. (1983). El poder empresarial en México. México: Terranova.

Cordero, S., y Santín, R. (1977). Los grupos industriales: una nueva organización económica en México. El Colegio de México.

Espinosa, E. (2007). La práctica historiográfica en Nuevo León. Una arqueología del conocimiento histórico regional, 1867-1996. Revista Secuencia, (68) 90-91.

Fuentes, J. (1976). Monterrey, una ciudad creadora y sus capitanes. México: Jus.

Garrido, C. (2002). Industrialización y grandes empresas en el desarrollo estabilizador, 1958-1970. Revista Análisis Económico, (35), 256.

González, M. (abril-junio, 1961). La ideología de la revolución mexicana. Revista Historia Mexicana, 40(4), 636.

Hansen, R. (1978). La política del desarrollo mexicano. México: Siglo XXI.

Hernández, E. (1985). La productividad y el desarrollo industrial en México. México: FCE.

Hidy, W. (1977). Historia de la empresa. En David L. Sills, Enciclopedia Internacional de las Ciencias Sociales, (5) 446-447.

Leal, J. (1972). El siglo diecinueve mexicano, el estado y las clases sociales 1821-1854. Revista Mexicana de Ciencias Políticas, (70) 6.

Marichal, C. (1997). Avances recientes en la historia de las grandes empresas y su importancia para la historia económica de México. En Carlos Marichal y Mario Cerutti (Comp.), Historia de las grandes empresas en México 1850-1930 (25-26).
Universidad Autónoma de Nuevo León FCE: México.

Marx, C. (1975). El Capital. Siglo XXI, Tomo I (3), 942.943.

Meyenberg, Y. (1993). La historia y la construcción del objeto de estudio. Revista Acta Sociológica, (7) $91-99$.

Pinto, A. (1991). América Latina: una visión estructuralista. México: UNAM.

Puga, C., y Torres, D. (1995). México: la modernización contradictoria. México: Alambra Mexicana.

Semo, E. (1973). Historia del Capitalismo en México. Los orígenes 1521-1723. México: Era.

Vellinga, M. (1988). Desigualdad, poder y cambio social en Monterrey. México: Siglo XXI.

Revista Expansión, No. 347, 18 de agosto de 1982, Pág. 142.

Periódico Oficial del Estado de Nuevo León, 3 de diciembre de 1927.

Revista Expansión, No. 257, 19 de enero de 1979. 
Universidad Juárez

Autónoma de Tabasco

"Estudio en la duda, acción en la fe"

\section{EDUCACION CONTINUA}

DA CEA

Contamos con Cursos y Talleres especializados

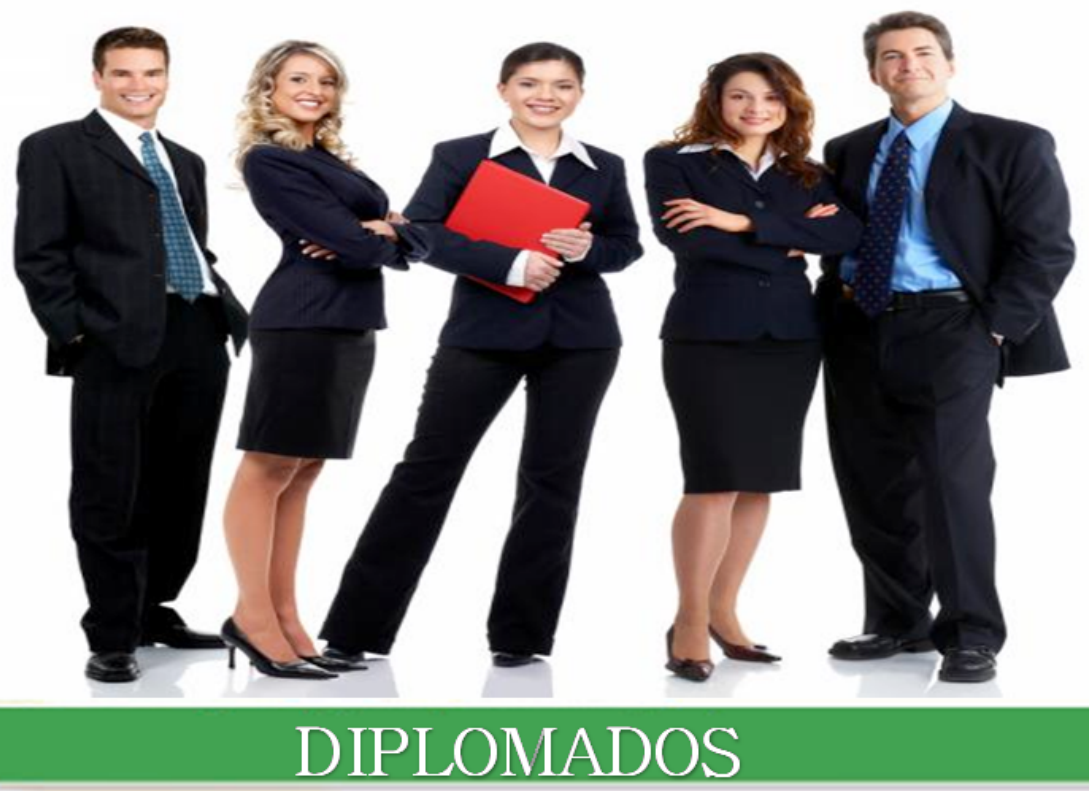

- Lineamientos y Fundamentos Metodológicos para la Elaboración de Tesis en los

Estudios de Posgrado (Egresados de Posgrado)

contabilidad Financiera

Contribuciones Fiscales

Mercadotecnia de Servicios

Desarrollo de Habilidades Administrativas

Desarrollo del Factor Humano en la Administración

\section{DIMISIÓN ACADÉMICA DE CIENCIAS ECONÓMICAS Y ADMINISTRATIVAS}

Mtro. William Baldemar López Rodríguez

Coordinador de Educación Continua

\section{Lic. Irene Zapata Jiménez \\ Asistente}

\section{EDIFICIO DE EDUCACIÓN CONTINUA Y A DISTANCIA}

TELEFONO: 3581567 EXT. 6219

Correo electrónico: educacioncontinua.dacea@ujat.mx 